\title{
Análise quanti-qualitativa do estado da degradação de bacia hidrográfica
}

A ideia de impacto ambiental, às vezes, pode provocar diferentes observações ou entendimentos sobre o meio físico natural, principalmente no que diz respeito a questão estrutural do substrato, e também sobre os processos geodinâmicos externos relacionados a degradante atividade de uso e ocupação solos. Assim, os recursos financeiros que podem ser disponibilizados com atividades de mitigação (e/ou recuperação) ambiental, e a possibilidade de soluções de engenharia são capazes de descrever (ou levantar) as diferenças entre degradação e estado de Degradação (eD). Logo, o objetivo deste trabalho é o de apresentar um procedimento interdisciplinar, que permita mesclar também as geociências e a engenharia para gestão geoambiental do território. Considerando para a avaliação do impacto ambiental, índices de degradação estimados e reconhecidos em função da extensão, dos efeitos de repercussão (em áreas vizinhas e longínquas), da intensidade dos efeitos (como destruições diversas) e da viabilidade de obras de mitigação em função de custos pecuniários e tempos de retorno. Neste caso, ficou constatado que a metodologia utilizada, desenvolvida por Martins Júnior (2014) apresentou um resultado de avaliação de impacto ambiental razoável, ao observar as magnitudes dos impactos ambientais da área de estudo.

Palavras-chave: Degradação; Cerrado; Norte de Minas Gerais.

\section{Quantitative-qualitative analysis of the status of river basin degradation}

The idea of environmental impact can sometimes provoke different observations or understandings about the natural physical environment, especially with respect to the structural issue of the substrate, as well as external geodynamic processes related to degrading activity of use and occupation alone. Thus, the financial resources that can be made available with environmental mitigation (and/or recovery) activities, and the possibility of engineering solutions are able to describe (or raise) the differences between degradation and degradation (eD). Therefore, the objective of this work is to present an interdisciplinary procedure, which also allows the merging of geosciences and engineering for geoenvironmental management of the territory. Considering for the assessment of the environmental impact, estimated and recognized degradation rates by extension, by-pass effects (in neighboring and remote areas), the intensity of the effects (such as various destruction) and the feasibility of mitigation works due to Pecuniary costs and times of return. In this case, it was verified that the methodology used, developed by Martins Júnior (2014) presented a reasonable environmental impact assessment result, when observing the magnitudes of the environmental impacts of the study area.

Keywords: Degradation; Cerrado; North of Minas Gerais.

Topic: Sistemas de Gestão Ambiental

Reviewed anonymously in the process of blind peer.
Received: $14 / 12 / 2017$

Approved: 24/01/2018
Marcilio Baltazar Teixeira (iD)

Universidade Federal do Pampa, Brasil

http://lattes.cnpq.br/0041228990178746

http://orcid.org/0000-0003-1310-3837

marciliobaltazar@hotmail.com

Pedro Luiz Teixeira de Camargo

Universidade Federal de Ouro Preto, Brasil

http://lattes.cnpq.br/4123026034662869

http://orcid.org/0000-0003-2652-4323

pedroluizteixeiradecamargo@yahoo.com.br

Paulo Pereira Martins Júnior

Universidade Federal de Ouro Preto, Brasil

http://lattes.cnpq.br/1323327733767945

maerteyn@gmail.com

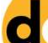

DOI: 10.6008/CBPC2179-6858.2018.002.0028
Referencing this:

TEIXEIRA, M. B.; CAMARGO, P. L. T.; MARTINS JÚNIOR, P. P.. Análise quanti-qualitativa do estado da degradação de bacia hidrográfica. Revista Ibero Americana de Ciências Ambientais, v.9, n.2, p.351-364, 2018. DOI: http://doi.org/10.6008/CBPC2179-6858.2018.002.0028 


\section{INTRODUÇÃO}

A noção de degradação implica em várias visões sobre o meio ambiente, especialmente sobre a estrutura do substrato e as questões geodinâmicas superficiais sob impacto das atividades de ocupação territorial. Não menos, deve-se pensar sobre a dimensão econômica deste tema, ainda muito mal realizado ao se considerar a perda de qualidade das terras de propriedades rurais e do processo de degradação das bacias hidrográficas.

O assunto é complexo o suficiente para deixar os efeitos serem apenas considerados sob o aspecto da mitigação, esquecendo-se da viabilidade técnica e econômica. Esses dois sujeitos podem levar a conclusão de que certos graus de degradação sejam absolutamente irreversíveis como mostram artigos publicados por Martins Júnior et al. (2006, 2008a, 2008b, 2010).

Ante a complexidade do mundo real o 'estado de degradação' está para o 'estado de conservação' de um modo antitético conforme os setores dos tipos de impactos. Tornam-se conceitos difíceis de parametrizar e delimitar. Com os custos operacionais efetivos para mitigar e a possibilidade de soluções de engenharia tem-se uma gama de questões que permitem caracterizar o que vem a ser efetivamente a degradação e o estado de Degradação - eD. Assim deve-se entender que esta forma de fazer face a questão do 'estado de Degradação' - eD é inovadora, sendo, portanto, a temática central deste estudo.

A noção do que pode ser chamado de Natural que é usada e, portanto, as noções de degradação e de conservação, são particularmente condicionadas em determinados limites por noções econômicas que parecem justificadas tanto em um sistema natural como em um sistema produtivo, conforme os modos de articulação das relações nos sistemas naturais e outras exigências dos processos agrícolas bem como as eventuais necessidades de terras para produção de alimentos e produção de biomassa para energia.

Como definição, o estado de Degradação, eD, é o conjunto de processos dinâmicos, naturais e antrópicos induzidos, pelos quais alterações diminuem progressivamente a ordem então vigente em ambientes naturais, tendendo levar áreas das bacias hidrográficas e dos biomas a condições de irreversibilidade (MARTINS JÚNIOR, 2014). Ou seja, pode-se dizer, considerando a afirmativa anterior, que o estado de conservação 'eC/ $S_{b}$ ' possui a definição inversa ao do estado de degradação $\left(e D=1-e C / S_{b}\right)$. Pois, quanto mais reduzido $\mathrm{o}$ ' $\mathrm{eC} / \mathrm{S}_{\mathrm{b}}$ ', menor será a capacidade de auto regeneração, auto sustentação e recuperação natural do ambiente; aumentando assim, as condições de irreversibilidade. Cabe destacar que os métodos de pesquisa aqui descritos são do campo dos grupos de pesquisa das 'Geociências Agrárias e Ambientais' e 'Soluções Integradas em Ecologia Energia Economia e Gestão', ambos registrados no CNPq.

\section{METODOLOGIA}

\section{Objetivo}

Demonstrar proposições lógicas interdisciplinares semi-quantitativas e quantitativas com geociências e engenharias várias, próprias para a gestão geo-ambiental do estado de Degradação (eD=1$\left.\mathrm{eC} / \mathrm{S}_{\mathrm{b}}\right)$. 


\section{Área de estudo}

A área de estudo, apresentada na Figura 1, encontra-se inserida na bacia hidrográfica do rio Pandeiros - Unidade de Planejamento e Gestão dos Recursos Hídricos - UPGRH/SF9 na região norte-nordeste de Minas Gerais - que se destaca, de acordo com CODEMIG (2013) pela sua potencialidade mineral, agrícola e da silvicultura do eucalipto.

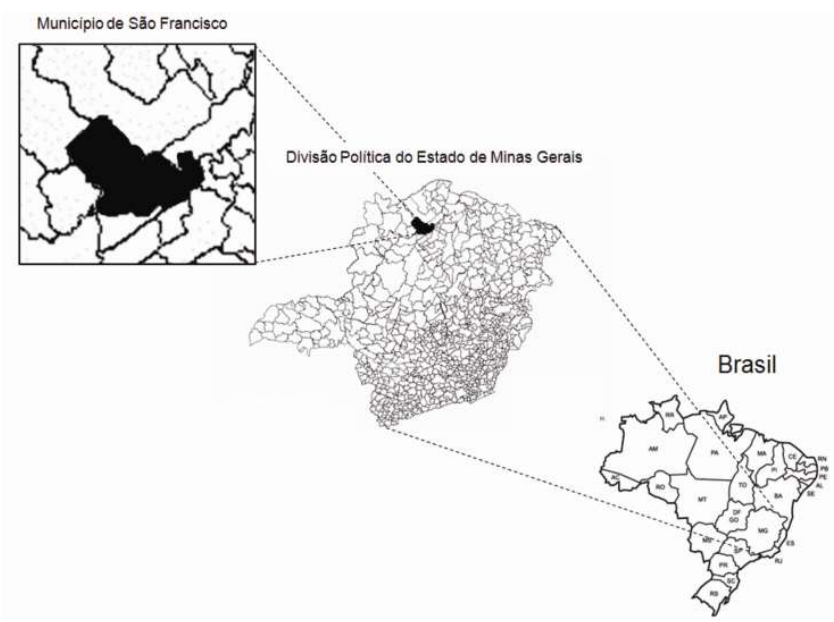

Figura 1: Localização do Município de São Francisco.

De maneira a melhor organizar o estudo em questão, o município de São Francisco foi dividido em 2 partes relativamente iguais, considerando-se como parâmetro natural de separação o próprio rio São Francisco, e denominando-se como Margem A, a porção de terras a localizadas a sudeste (direita), e B (local específico deste trabalho), a porção de terras situadas a noroeste (esquerda). A porção B foi avaliada por Teixeira (2016), como a parte do município mais degradada sob o ponto de vista da perda de vegetação original (Cerrado)

\section{Reconhecimento das Variáveis de Impactos Básicos e as de Repercussão}

As variáveis básicas primárias da localidade de interesse foram medidas utilizando-se as imagens do Google Earth, e geoprocessadas no software QGis, sendo coletadas as áreas e intensidades dos impactos (tamanhos das regiões impactadas em hectares, $\mathrm{m}^{2}$ ou $\mathrm{km}^{2}$ ). A intensidade foi avaliada comparando-se as mais diversas regiões impactadas com uma localidade de referência supondo-se esta área paradigma de impacto ambiental antrópico nula ou, paralelamente, considerada não degradada por atividades provocadas pelo homem. Assim, a intensidade do impacto pode ser caracterizada utilizando-se as imagens do LANDSAT, donde puderam ser obtidos os níveis de radiação da vegetação ou índice de vegetação por diferença normalizada NDVI - normalized difference vegetation index - para cada localidade impactada ao se comparar o índice $\left(N D V I_{D}\right)$ destas regiões com aquele $\left(N D V I_{R}\right)$ obtido na região de referência.

Os diversos índices de vegetação são utilizados para observar as condições da degradação e as distribuições espaciais da cobertura vegetal, através do uso das informações de reflectâncias do espectro eletromagnético ou da radiância dos objetos. Assim, possibilitam reunir os dados espectrais e discriminar os elementos que compõem o meio ambiente (como, por exemplo: entre o que é ou não vegetação), avaliando- 
se as adversidades do comportamento dos plantios e/ou da vegetação de uma maneira geral, diante dos eventos naturais e antrópicos. Brandão et al. (2007) relatam que a principal importância dos índices de vegetação incide em demarcar (ou realçar) áreas da vegetação sobre a superfície da região analisada.

Assim, Rouse et al. (1973) propôs que o NDVI deve ser estimado pela subtração das reflectâncias

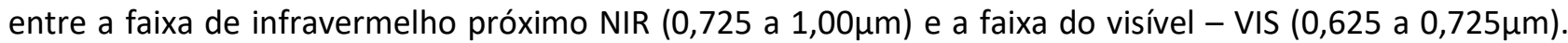
Observe a formulação a seguir, a proposta de Rouse et al. (1973) e utilizada nesta pesquisa: NDVI = [(NIR $\mathrm{VIS}) /(\mathrm{NIR}+\mathrm{VIS})]$. As variáveis de repercussão, para efeito deste estudo, foram consideradas todas aquelas que do ponto de vista físico ambiental e econômico atuam e levam as consequências do evento local a estender a degradação até outros pontos, fora da área imediata da degradação original. A partir desta análise, devese efetuar a avaliação das regiões impactadas de acordo com os índices semi-quantitativos, a seguir exposto.

\section{Índices semi-quantitativos}

Esses impactos também foram avaliados em função de: (1) áreas, como extensão total de ocorrência de cada impacto e do conjunto destes impactos associados a cada caso com repercussão, para todas as situações sem qualquer outra consideração; (2) área do impacto em si com mitigação possível (com tempo de retorno de até 2 anos); (3) mitigação ou reconstrução ainda possível (tempo de retorno entre 2 e 5 anos); (4) reconstrução ou restauração difícil com custos maiores, mas ainda possível (tempo de retorno de 10 a 15 anos); (5) com intervenções de máquinas necessárias para a reparação com interrupção de processo (tempo de retorno de 10 a 15 anos); (6) intervenções com máquinas e obras de engenharia, ou com ações de reocupação dos solos (tempo de retorno de 25 a 30 anos); (7) modificação da paisagem local ou não, com exigência de intervenção corretiva para interromper o processo + obras de engenharia (tempo de retorno $>30$ anos, <50anos); (8) dispersão irrecuperável (tempo de retorno > 50 anos); (9) degradação sem retorno e com custos irrecuperáveis.

Sugeridos por Martins Júnior (2014), os intervalos de tempo de retorno para a realizações de mitigação do impacto ambiental obedeceram às expectativas de sucessos progressivos em tempo hábeis para de fato se obter interrupção da dinâmica dos processos de degradação. Por outro lado, os índices semiquantittativos adotados foram tomados para a área de estudo como a unidade fundamental de avaliação ambiental. Assim, as questões abaixo (de 1 a 6) foram definidas a priori para que as atribuições de notas (ou dos índices semi-quantitativos) para o monitoramento da situação (ou da região impactada) se enquadrassem nas definições de limites, expostos adiante na Tabela 3, como modos efetivos de avaliar impactos e possibilidades, efeitos e custos de mitigação do meio ambiente.

Cabe ressaltar que as notas devem ser estimadas ou reconhecidas em função da área de um impacto, ou da área de mais de um impacto em uma mesma localidade/região, e/ou de uma sucessão de impactos ligados por relações causais comuns, que permitem calcular o significado dos impactos na área de estudo. Dessa forma, alguns aspectos relevantes que devem ser considerados no que diz respeito às áreas, elas foram dispostas no Quadro 1. 


\section{Quadro 1: Aspectos relevantes.}

1 - Qual a escala de observação e de representação e a acuidade possível de se representar o impacto?

2 - Trata-se somente de um único tipo de impacto?

3 - Ocorre mais de um tipo de impacto exclusivamente na mesma área de tal modo que se possa reconhecer uma área total integral de impacto?

4 - Uma área impactada é fonte de outros tipos de impactos em locais mais longínquas de modo que não se possa reconhecer que a área total de impacto seja contínua?

5 - O impacto único, ou múltiplo, afeta diversos sistemas distintos e de modo correlato a partir de uma única causa?

6- O impacto único, ou múltiplo, afeta diversos sistemas distintos e de modo sequencial a partir de uma sucessão de causas não correlatas?

Essas seis perguntas perfazem um quadro de relações causais que permite a priori caracterizar-se qual é efetivamente a área de impacto para então expressar as medidas possíveis para cada situação. Cabe ressaltar que os valores percentuais, assim como estão representados adiante na Tabela 3, são intervalos para se enquadrar os impactos observados e medidos. Ou seja, as notas devem ser estimadas ou reconhecidas em função de: áreas locais; intensidade dos efeitos como destruições diversas nas vizinhanças imediatas; efeitos de repercussão ainda considerados em áreas vizinhas e áreas longínquas; viabilidade de obras de mitigação em função de custos pecuniários e tempos de retorno.

As condições devem ser estabelecidas para os seguintes temas operacionais: Avaliação de mitigação por área com as técnicas existentes e os estudos de riscos de insucessos; Avaliação de mitigação por área com as técnicas existentes e o estudo de não retornos econômicos para o produtor rural; As superfícies de áreas degradadas por tipos de degradação no total da área da bacia hidrográfica, também por setores contíguos e/ou por setores com estruturas equivalentes, não importando quanto estejam separados dentro da área da bacia; A avaliação dos custos de se atuar em projetos de mitigação de modo contínuo seja nos setores contíguos seja em setores com estruturas equivalentes em áreas diversas da bacia hidrográfica; 0 estudo do conjunto de técnicas e de seus custos de aplicação efetivos ante as características de cada área degradada; Os estudos para aplicação com técnicas que possam envolver retornos econômicos com a mitigação; Modelar a parte dos custos que possam ser transformadas em aplicação econômica e, portanto, abatidos; e Estimar as taxas de retorno possíveis com os custos transformados em investimentos com projetos específicos.

No que diz respeito aos processos de repercussão, a noção de índices é o de mais complexa feição, todavia, se faz necessária à sua produção. As sucessões de repercussões, sem dúvida, produzem efeitos diversos, em sucessão, no espaço e no tempo. Apesar dos aspectos semi-quantitativos apresentados conterem graus de imprecisão, permitem determinar uma 'ordem de grandeza dos impactos' e das medidas de mitigação a considerar. As faixas escolhidas para avaliação de impacto ambiental têm valores definidos de modo qualitativo/ semi-quantitativo e como predeterminantes de limites considerados lógicos. Assim o Tabela 1 apresenta onde estas podem ser encontradas.

Para complementar o raciocínio da avaliação do impacto ambiental, os índices de degradação foram estimados e reconhecidos em função da extensão, dos efeitos de repercussão (em áreas vizinhas e longínquas), da intensidade dos efeitos (como destruições diversas) e da viabilidade de obras de restauro em função de custos pecuniários e tempos de retorno. 
Tabela 1: Localização dos índices semi-quantitativos e processos de repercussão consequentes

\begin{tabular}{|l|l|}
\hline Citação & Tipo de Informação \\
\hline $\begin{array}{l}\text { Tabela } 1 \text { apresentada } \\
\text { em Martins Júnior } \\
(2014)\end{array}$ & $\begin{array}{l}25 \text { tipos de degradação básicos, considerados com indicações dos fatores de repercussão desses } \\
\text { impactos típicos em relação às consequências mediatas }\end{array}$ \\
\hline $\begin{array}{l}\text { Tabela } 2 \text { apresentada } \\
\text { em Martins Júnior } \\
(2014)\end{array}$ & $\begin{array}{l}\text { Intervalos deduzidos para expressar e/ou enquadrar níveis de criticidade dos impactos ambientais em } \\
\text { funão dos diversos métodos de expressar impactos únicos e impactos múltiplos. }\end{array}$ \\
\hline $\begin{array}{l}\text { Tabela } 3 \text { apresentada } \\
\text { em Martins Júnior } \\
\text { (2014) }\end{array}$ & $\begin{array}{l}\text { Relação dos 24 tipos de degradação e descrições das mesmas em relação a um índice semi-quantitativo às áreas, a intensidade e a repercussão do processo degradacional. Os índices em percentuais } \\
\text { devem ser enquadrados para as relações área/intensidade/repercussão. }\end{array}$ \\
\hline
\end{tabular}

Portanto, cabem as soluções preventivas e de conservação evitar futuros esforços de mitigação e de revitalização. Estas soluções podem ser realizadas como forma de prevenção ou parte da política ambiental e cultural de conservação da bacia hidrográfica (do local escolhido). Dessa forma, para entender o nível de conservação da área de estudo, frente a cada impacto identificado, tendo conhecimento da extensão do impacto e dos tipos de usos e ocupações do solo, calculou-se o estado de Conservação $\left(e C / S_{b}\right)$ segundo Martins Júnior (2014):

$$
\left.e C / S_{b}=S_{b}-S_{a d}\left(f S_{a t, i=(1 a n<15)}\right) \times\left[f \sum i m p_{(1, n)}\right]\right)
$$

Onde: $\mathrm{eC} / \mathrm{S}_{\mathrm{b}}=$ estado de Conservação; sendo estado de Degradação: $\mathrm{eD}=1-\mathrm{eC} / \mathrm{S}_{\mathrm{b}}$.

$\mathrm{S}_{\mathrm{b}}$ - área total da bacia (região avaliada) Sad - superfície total de áreas degradadas [? - função de 1 a $n$ tipos de impactos []Sat - somatório das superfícies de áreas degradadas por tipos de degradação com indicação da intensidade dos impactos. imp - função dos impactos efetivos em cada área.

Os cálculos do estado de Degradação $\left(e D=1-e C / S_{b}\right)$ devem indicar as áreas a serem monitoradas rotineiramente e aquelas que não necessitam de cuidados imediatos. Considera-se que quanto mais grave a situação da área de estudo, sob o ponto de vista do funcionamento dos sistemas naturais, menor será o estado de Conservação $(\mathrm{eC})$. Se eC for muito baixo, maior será o tempo de retorno para que as condições ambientais retornem ao estado natural anterior ao do estabelecimento do impacto, mesmo com a intervenções mitigadoras ou de engenharia. Assim, quanto menor eC de uma determinada localidade, maior será a prioridade a intervenções (de mitigação biológica ou de engenharia) por oferecerem elevados riscos de reversibilidade reconhecível como possível.

\section{RESULTADOS E DISCUSSÃO}

\section{Estudo do Caso (ou da problemática): Avaliação do Estado da Degradação (eD) do Município de São} Francisco (MG)

A avaliação do impacto ambiental na área de interesse reserva-se, especificamente, para a localidade inserida no interior de uma região que foi considerada como a mais impactada pelo estudo de caracterização da degradação do cerrado, a qual utilizou-se imagens dos sensores remotos (LandSat 5 - TM), entre os anos de 1973/1975 a 2011. Este estudo está exposto em Teixeira et al. (2016). A partir de então, realizou-se os estudos nas escalas de 1:250.000, 1:150.000, 1:50.000, 1:10.000 e 1.300. Com isso, foi possível detectar 
alguns dos principais impactos ambientais que ocorrem na área de estudo, de acordo com o proposto por Martins Júnior (2014) e em conformidade com o descrito na Tabela 1.

Assim, pode-se identificar 6 tipos de impactos típicos no local de acordo com o apresentando na Tabela 2 (abaixo) e considerando-se os tipos de usos e ocupações do solo mais comuns encontrados na área específica de trabalho, conforme prevê os Recibos de Inscrição de Imóvel Rural cedidos pelo Instituto Estadual de Florestas de Minas Gerais (IEF). Considera-se também, para isto, o Anexo III do Parecer Único (Agenda Verde) do Núcleo de Regularização Ambiental do Município de São Francisco.

Tabela 2: Impactos típicos encontrados na área de estudo de acordo com a Metodologia de Martins Júnior (2014).

\begin{tabular}{|c|c|}
\hline Impactos típicos & $\begin{array}{l}\text { Características de repercussão de natureza geológico- } \\
\text { geotécnica }\end{array}$ \\
\hline 1-Encrostamento localizado de solos & a) aumenta o escoamento superficial durante chuvas. \\
\hline $\begin{array}{l}\text { 2- Desmatamento controlado realizado } \\
\text { com conservação de sistemas naturais }\end{array}$ & $\begin{array}{l}\text { b) espera-se se produzir impactos ambientais diversos } \\
\text { sem repercussão. }\end{array}$ \\
\hline 3 - Desmatamento extensivo e capaz de aniquilar ecossistemas & $\begin{array}{l}\text { c) pode afetar a circulação hídrica. } \\
\text { d) pode atuar como indutor de erosão. }\end{array}$ \\
\hline 4 - Enrijecimento de solos com pisoteio de gado & $\begin{array}{l}\text { e) produção de caminhos nas vertentes. } \\
\text { f) endurecimento progressivo dos caminhos. } \\
\text { g) endurecimentos do solo na pastagem. } \\
\text { h) eventual aumento de escoamento superficial. }\end{array}$ \\
\hline $\begin{array}{l}5 \text { - Produção de descontinuidade floral ao longo do bioma com } \\
\text { remanescentes de matas isoladas }\end{array}$ & $\begin{array}{l}\text { i) alteração possível da circulação hídrica. } \\
\text { j) impactos possíveis sobre o solo. } \\
\text { k) eventualmente favorece erosão. }\end{array}$ \\
\hline 6 - Indução à erosão propiciada pela construção de vias. & $\begin{array}{l}\text { l) erosão nas vertentes para fora da estrada. } \\
\text { m) erosão de vertentes sobre a estrada. } \\
\text { n) erosão da própria estrada. } \\
\text { o) desestruturação da paisagem. } \\
\text { p) perda de solos. } \\
\text { q) aumento de sedimentos em circulação. }\end{array}$ \\
\hline
\end{tabular}

O tipo de Uso e Ocupação do Solo mais comum encontrado nesta região é a atividade agrosilvopastoril. Contudo, estes impactos identificados para a área experimental localizada na área mais degradada do município de São Francisco, foram avaliados, de acordo com os índices de intensidade da degradação sugeridos por Martins Júnior (2014), segundo aponta a Tabela 3.

No entanto, Martins Júnior (2014) convencionou estes índices da degradação, considerando as diversas situações reconhecidas nas regiões Noroeste e Norte de Minas Gerais, consideradas exemplares, em que se podem observar os mais variados impactos ambientais existentes e padronizá-los, considerando ainda as variáveis socioeconômicos e ambientais. Assim como a maioria das metodologias que transformam informações qualitativas em parâmetros quantitativos, como se pode observar também em diversas metodologias de mensuração monetária presentes na Economia Ambiental como no caso das dissertações de Camargo (2014), Tafuri (2010) e a tese de Oliveira Júnior (2007), está também se baseia na subjetividade e dedução, pois a adoção de quantidades depende do avaliador.

Tabela 3: Índices de Intensidade da Degradação.

\begin{tabular}{|c|c|c|c|c|c|c|}
\hline \multicolumn{7}{|c|}{ Percentuais limites definidos segundo expectativas de estado de degradação } \\
\hline \multirow{3}{*}{ Impacto Típicos } & baixo & baixo a médio & médio inferior & médio superior & superior & máximo \\
\hline & $\begin{array}{l}<10 \% \\
\text { até } 10 \%\end{array}$ & $\begin{array}{l}>11 \% \\
\text { até } 20 \%\end{array}$ & $\begin{array}{l}>21 \% \\
\text { até } 50 \%\end{array}$ & $\begin{array}{l}>51 \% \\
\text { até } 65 \%\end{array}$ & $\begin{array}{l}>66 \% \\
\text { até } 85 \%\end{array}$ & $\begin{array}{l}>86 \% \\
\text { até } 100 \%\end{array}$ \\
\hline & - & - & - & - & A considerar inaceitável & $\begin{array}{l}\text { A considerar } \\
\text { inaceitável }\end{array}$ \\
\hline
\end{tabular}




\begin{tabular}{|l|l|l|l|l|l|l|}
\hline $\mathbf{1}$ & $\mathrm{X}$ & - & - & - & - \\
\hline $\mathbf{2}$ & $\mathrm{X}$ & - & - & - & - & - \\
\hline $\mathbf{3}$ & $\mathrm{X}$ & & - & - & - & - \\
\hline $\mathbf{5}$ & $\mathrm{X}$ & - & - & - & - & - \\
\hline $\mathbf{5}$ & - & - & $\mathrm{X}$ & - & - & - \\
\hline
\end{tabular}

Legenda: Em negrito está o intervalo considerado para cada impacto encontrado na área de estudo.

No entanto, Martins Júnior (2014) convencionou estes índices da degradação, considerando as diversas situações reconhecidas nas regiões Noroeste e Norte de Minas Gerais, consideradas exemplares, em que se podem observar os mais variados impactos ambientais existentes e padronizá-los, considerando ainda as variáveis socioeconômicos e ambientais. Assim como a maioria das metodologias que transformam informações qualitativas em parâmetros quantitativos, como se pode observar também em diversas metodologias de mensuração monetária presentes na Economia Ambiental como no caso das dissertações de Camargo (2014), Tafuri (2010) e a tese de Oliveira Júnior (2007), está também se baseia na subjetividade e dedução, pois a adoção de quantidades depende do avaliador.

Desta forma, apontam-se os mais variados e diferentes 'períodos de retorno de recuperação' - PRR, em função da extensão, intensidade e repercussão do processo degradacional da área de interesse. Segundo Martins Júnior (2014), para a avaliação dos impactos ambientais e a indicação dos índices da degradação foram considerados os vários tempos de retornos (Tabela 4) positivos de realizações de mitigação.

Tabela 4: Tempo de retorno.

\begin{tabular}{|l|l|}
\hline Código & Considerações de Tempo de Retorno \\
\hline A & Área do impacto em si com mitigação possível (tempo de retorno até 2 anos) \\
\hline B & Mitigação ou reconstrução ainda possível (tempo de 2 a 5 anos) \\
\hline C & Reconstrução ou restauração difícil com custos maiores, mas ainda possível (tempo de retorno de 10 a15 anos) \\
\hline D & $\begin{array}{l}\text { Com intervenções de máquinas necessárias para a reparação com interrupção de processo (tempo de retorno de } 10 \text { a } \\
15 \text { anos) }\end{array}$ \\
\hline E & $\begin{array}{l}\text { Intervenções com máquinas e com obras de engenharia, ou com ações de reocupação dos solos (tempo de retorno de } \\
25 \text { a } 30 \text { anos) }\end{array}$ \\
\hline
\end{tabular}

Após o cálculo do estado de Degradação (eD), é importante considerar que as áreas das localidades de estudo foram obtidas a partir da vetorização em tela das imagens do GoogleEarth, utilizando o software livre QGIS. Destaca-se que o software QGIS realiza automaticamente a correção das distorções geométricas das imagens do GoogleEarth, facilitando o trabalho de organização vetorial por parte dos autores do trabalho em questão. Em seguida, procurou-se conhecer qual era a classificação da intensidade do estado de Degradação $\left(e D=1-e C / S_{b}\right)$ de acordo com os Tabelas 5 e 6.

Tabela 5: Níveis do estado de Conservação (eD = 1-eC/ $\left.\mathrm{S}_{\mathrm{b}}\right)$.

Percentuais limites definidos segundo expectativas de estado de Conservação (eD)

\begin{tabular}{|c|c|c|c|c|c|c|}
\hline \multirow{3}{*}{ eD } & baixo & baixo a médio & médio inferior & médio superior & superior & máximo \\
\hline & $\begin{array}{l}<10 \% \\
\text { até } 10 \%\end{array}$ & $\begin{array}{l}>11 \% \\
\text { até } 20 \%\end{array}$ & $\begin{array}{l}>21 \% \\
\text { até } 50 \%\end{array}$ & $\begin{array}{l}>51 \% \\
\text { até } 65 \%\end{array}$ & $\begin{array}{l}>66 \% \\
\text { até } 85 \%\end{array}$ & $\begin{array}{l}>86 \% \\
\text { até } 100 \%\end{array}$ \\
\hline & & & & & A considerar inaceitável & $\begin{array}{l}\text { A considerar } \\
\text { inaceitável }\end{array}$ \\
\hline
\end{tabular}

* Valores de 'eD' expressos em porcentagem (eD x 100).

Tabela 6: estado de Degradação $\left(e \mathrm{eD}=1-\mathrm{eC} / \mathrm{S}_{\mathrm{b}}\right)$ das localidades estudadas.

\begin{tabular}{|l|l|l|l|l|l|l|}
\hline $\begin{array}{l}\text { Temas - Uso e Ocupação do Solos } \\
\text { Ver }\end{array}$ & $\begin{array}{l}\text { Tipo de Área } \\
\text { Impacto }\end{array}$ & $\begin{array}{l}\text { Intensidade } \\
\left(\mathrm{Km}^{2}\right)\end{array}$ & $\begin{array}{l}\text { Tempo de } \\
\text { retorno }\end{array}$ & Custos & eD \\
\hline
\end{tabular}




\begin{tabular}{|c|c|c|c|c|c|c|}
\hline Figura 2 & $\begin{array}{l}\text { Ver } \\
\text { Tabela } 2 \\
\end{array}$ & & $\begin{array}{l}\text { Ver } \\
\text { Tabela } 3 \\
\end{array}$ & $\begin{array}{l}\text { Ver } \\
\text { Tabela } 4 \\
\end{array}$ & $\begin{array}{l}\text { Ver } \\
\text { Tabela } 10 \\
\end{array}$ & $\begin{array}{l}\text { Ver } \\
\text { Tabela } 5 \\
\end{array}$ \\
\hline \multirow[b]{2}{*}{ Pastagens } & \multirow[b]{2}{*}{4} & \multicolumn{4}{|c|}{ Quantidade do Tema: UMA área de pastagem } & \multirow{2}{*}{$\begin{array}{l}1,66 \% \\
(\mathrm{~T}) \\
21,0 \% \\
(\mathrm{P})\end{array}$} \\
\hline & & (1) 2,27 & $21 \%$ & Código C & $\begin{array}{l}\text { Custo } \\
\text { Fixo }\end{array}$ & \\
\hline \multirow[b]{2}{*}{ Mata de Galeria Impactada } & \multirow[b]{2}{*}{3} & \multicolumn{4}{|c|}{ Quantidade do Tema: DUAS áreas de Mata de Galeria } & \multirow{2}{*}{$\begin{array}{l}0,90 \% \\
(\mathrm{~T}) \\
6,03 \% \\
(\mathrm{P})\end{array}$} \\
\hline & & $\begin{array}{l}\text { (1) } 0,14 \\
\text { (2) } 4,15\end{array}$ & $\begin{array}{l}7 \% \\
6 \%\end{array}$ & Código A & $\begin{array}{l}\text { Custo } \\
\text { Fixo }\end{array}$ & \\
\hline \multirow[b]{2}{*}{ Silvicultura } & \multirow[b]{2}{*}{3 e 5} & \multicolumn{4}{|c|}{ Quantidade do Tema: QUATRO áreas de silvicultura } & \multirow[b]{2}{*}{$\begin{array}{l}6,27 \% \\
(T) \\
21,3 \% \\
(P)\end{array}$} \\
\hline & & $\begin{array}{l}\text { (1) } 0,04 \\
\text { (2) } 0,06 \\
\text { (3) } 0,37 \\
\text { (4) } 7,99\end{array}$ & $\begin{array}{l}26 \% \\
29 \% \\
25 \% \\
21 \% \\
\end{array}$ & Código C & $\begin{array}{l}\text { Custo } \\
\text { Fixo }\end{array}$ & \\
\hline \multirow[b]{2}{*}{$\begin{array}{l}\text { Regiões de Vegetação Nativa } \\
\text { Remanescentes } \\
\text { (Cerrado) }\end{array}$} & & \multicolumn{4}{|c|}{ Quantidade do Tema: SEIS áreas de Cerrado } & \multirow[b]{2}{*}{$\begin{array}{l}10,2 \% \\
(\mathrm{~T}) \\
22,0 \%( \\
\mathrm{P})\end{array}$} \\
\hline & 2,3 e 5 & $\begin{array}{l}\text { (1) } 0,14 \\
\text { (2) } 4,15 \\
\text { (3) } 0,11 \\
\text { (4) } 2,22 \\
\text { (5) } 3,13 \\
\text { (6) } 3,61\end{array}$ & $22 \%$ & Código C & $\begin{array}{l}\text { Custo } \\
\text { Fixo }\end{array}$ & \\
\hline \multirow[b]{2}{*}{ Estrada Não Pavimentada } & \multirow[b]{2}{*}{1 e 6} & \multicolumn{4}{|c|}{ Quantidade do Tema: UMA áreas de Estradas } & $0,52 \%$ \\
\hline & & (1) 0,29 & $51 \%$ & Código D & $\begin{array}{l}\text { Custo } \\
\text { Fixo }\end{array}$ & $\begin{array}{l}(\mathrm{T}) \\
51,0 \% \\
(\mathrm{P})\end{array}$ \\
\hline
\end{tabular}

* Valores de 'eD' expressos em porcentagem (eD x 100). (T) Valores em relação a área total avaliada. (P) Valores em relação a área do tema impactado.

Os resultados de 'eC' apontam que a região (ou a temática) mais degradada são as áreas de pastagens e estradas não pavimentadas (Tabela 6), constituindo um resultado que as classificam, de acordo com a Tabela 5, como de baixa conservação, ou seja, de acordo com estas análises, nestas regiões a capacidade de auto recuperação do sistema natural encontra-se completamente comprometida, considerada como um ativo ambiental irreversível. As margens dos cursos d'água não seguem o mesmo raciocínio aplicado anteriormente para a sua avaliação ambiental.

Nas regiões de vegetação nativa remanescente (cerrado) e silvicultura, nota-se uma avaliação ambiental que as caracterizam como no nível médio do estado de Conservação (eC). Ou seja, apesar do cerrado estar amplamente degradado; e de alguns locais esta vegetação ter sido substituída pela silvicultura, deduz-se que os sistemas naturais podem não ter perdido totalmente a sua capacidade de autorregenerarão ou auto sustentação.

$\mathrm{O}$ eC fortemente baixo indica que o ambiente pode ter perdido a sua capacidade de recuperação natural intrínseca; assim, mesmo com apoio de técnicas antrópicas de recuperação de áreas degradadas, tais áreas são de difícil recomposição vegetal. Essas características não se aplicam às localidades que possuem vegetação nativa remanescente (cerrado) e silvicultura. No caso desta pesquisa, avaliou-se apenas a perda de vegetação e sua repercussão impactante de natureza geotécnica, tais como: perda de solo por erosão, redução da capacidade de infiltração das águas pluviais, aumento do escoamento superficial e enrijecimento dos solos.

As Figura 2 e 3 apresentam para duas épocas distintas, respectivamente para os anos de 1964 e 2011, alguns tipos de uso e ocupação do solo, demonstrando de maneira aparentemente básica, uma localidade 
caracterizada como de baixo índice do estado de Conservação eC, para isto considerando todos os tipos de uso e ocupação do solo, tais como: pastagens, margens de cursos d'água, regiões de vegetação nativa remanescentes (cerrado) e estradas não pavimentadas.

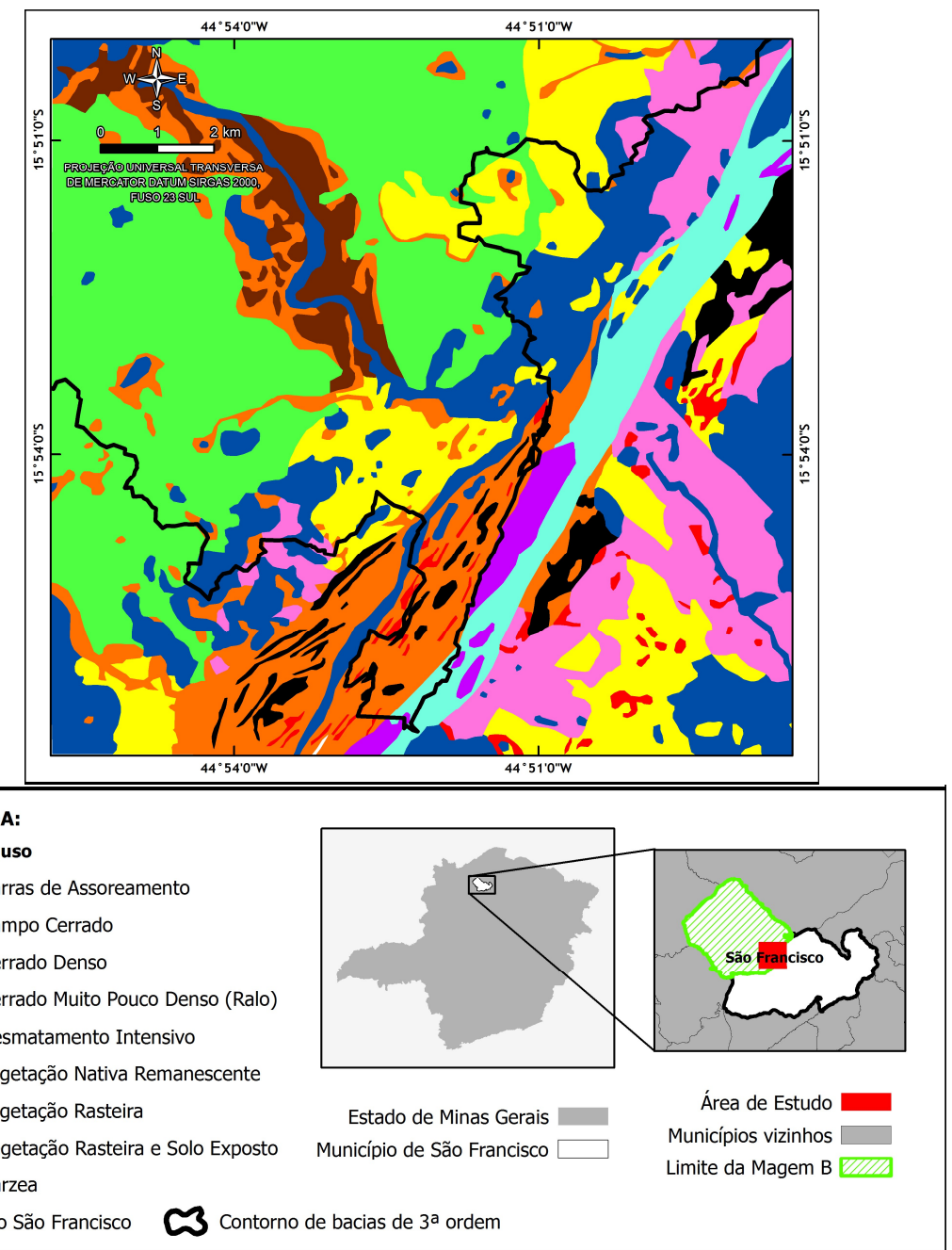

Figura 2: Região da borda Sul da localidade selecionada inserida em bacias de 3a ordem (ver Figura 3) e caracterizada como a que possui elevado estado de Degradação (eD) para o ano de 2011- Informações relativas ao ano de 1964.

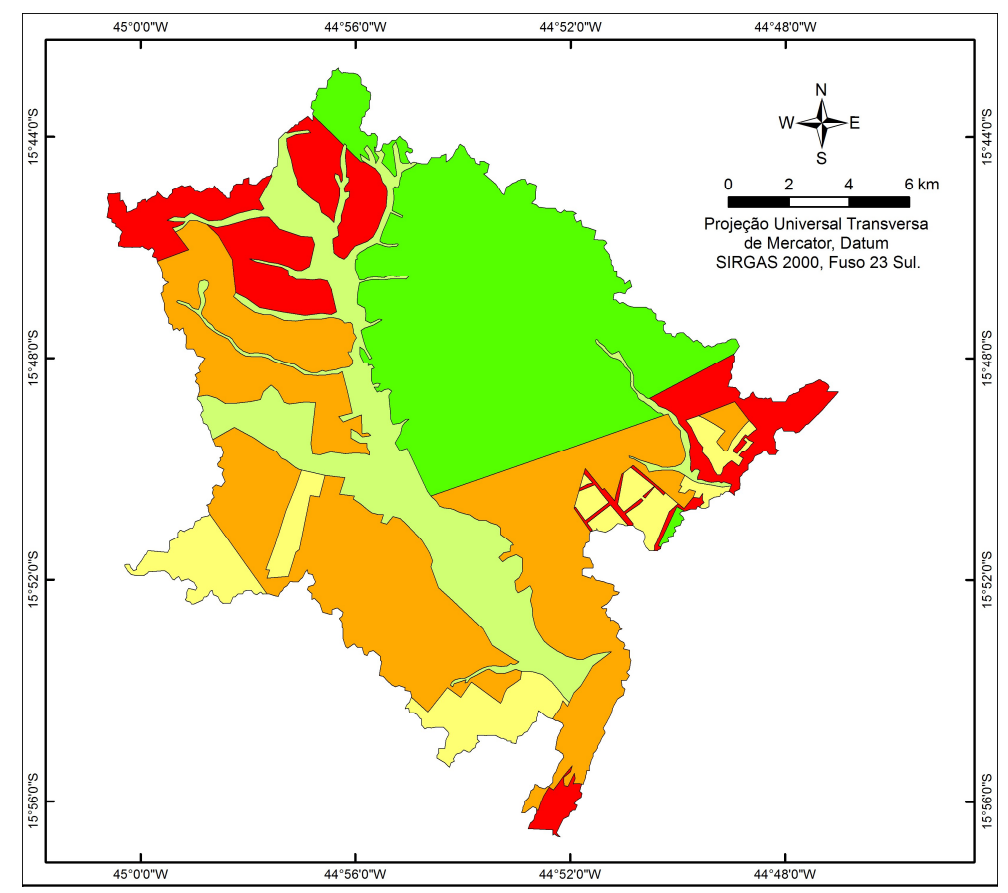




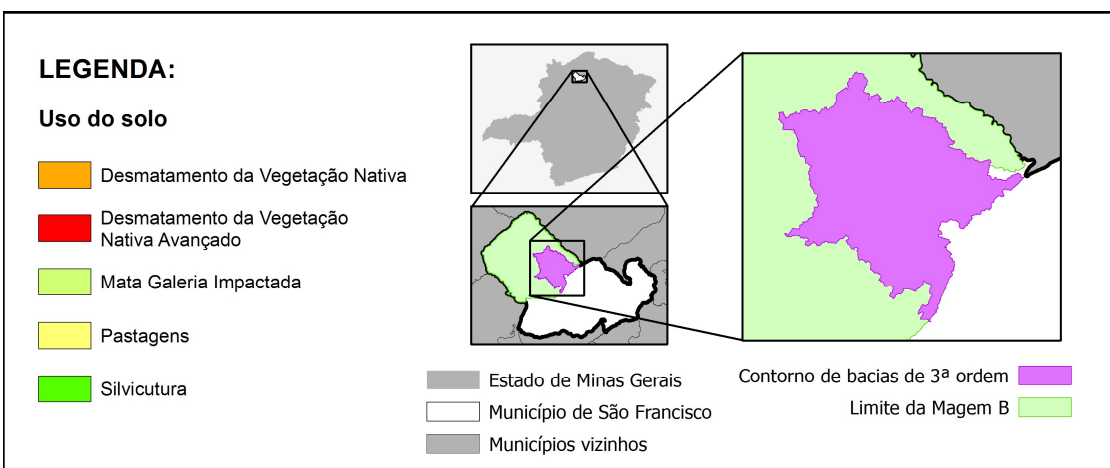

Figura 3: Localidade de interesse considerada como bacia de 3a ordem e caracterizada por possuir elevado estado de Degradação (eD) - Informações relativas ao ano de 2011.

Assim, nestas regiões expostas anteriormente a ação antrópica alterou completamente as condições naturais, assim como também os tipos de usos do solo ao longo de quase 50 anos. Dessa forma, a metodologia utilizada neste trabalho; de avaliação do impacto ambiental, possibilitou indicar de forma clara as áreas naturais que sofrem (ou sofreram) maior impacto com a intervenção humana ao longo do tempo. Permitindo a identificação de maneira satisfatória das regiões críticas (sob o ponto de vista da conservação ambiental), que por outro lado, os resultados provenientes deste estudo coincidiram com a avaliação de campo.

Ainda seguindo a metodologia de Martins Júnior (2014) para avaliar o impacto ambiental no município de São Francisco, em Minas Gerais; este ainda sugere algumas soluções às intervenções nas áreas impactadas. Assim, na Tabela 7 estão apresentadas algumas das técnicas e procedimentos de recuperação possíveis na área em questão.

Por outro lado, também a Engenharia Aplicada ao Meio Rural oferece outros recursos para recuperação de áreas degradadas. Assim, para o local de interesse foram sugeridas algumas soluções adaptáveis ao meio rural, como forma de se tentar prevenir, remediar e recuperar o dano ambiental. Tais soluções são apresentadas na Tabela 8.

Tabela 7: Soluções propostas (MARTINS JÚNIOR, 2014).

\begin{tabular}{|l|l|}
\hline $\begin{array}{l}\text { Impactos e/ou } \\
\text { Degradação }\end{array}$ & Técnicas e Procedimentos \\
\hline 1 & a) Subsolagem e replantio em áreas isoladas de encrostamento \\
\hline 2 & b) desmatamento autorizado com base em estudos de manutenção da interconectividade floral do bioma \\
\hline 3 & $\begin{array}{l}\text { c) Recomposição de corredores florestais ecológicos e econômicos e conexão com remanescentes de maciços } \\
\text { florestais e florestas de galerias; conservação dos biomas em áreas estratégicas; restauração dos biomas em } \\
\text { áreas estratégicas. }\end{array}$ \\
\hline 4 & $\begin{array}{l}\text { d) Tema sem solução se o gado pisotear; a solução está em algum tipo de semi-confinamento; nas áreas } \\
\text { degradadas a subsolagem e o replantio devem ser a solução. }\end{array}$ \\
\hline 5 & e) Reintegrar as matas remanescentes com corredores florestais ecológicos e ecológico-econômicos. \\
\hline 6 & $\begin{array}{l}\text { f) Revisão de todas as vias com identificação dos locais de indução da erosão e aplicação das correçães } \\
\text { devidas, como por exemplo, a construção de barragens de contenção do escoamento superficial; exigência } \\
\text { do órgão responsável de apresentar plano para evitar e/ou corrigir o processo erosivo. }\end{array}$ \\
\hline
\end{tabular}

Tabela 8: Soluções de Engenharia Aplicada ao Meio Rural.

\begin{tabular}{|l|l|l|}
\hline Características do Uso & Categorias de intervenção & Métodos \\
\hline Plantios e colheita mecanizados & & - Preservação da vegetação nativa, \\
Regiões de vegetação nativa & Detenção de água a & - Revegetação \\
remanescentes & montante & -Curva de nível \\
Vegetação Nativa & & \\
Vegetação plantada & & \\
\hline
\end{tabular}




\begin{tabular}{|c|c|c|}
\hline Estradas não pavimentadas & Obras de microdrenagem & - Sarjeta escavada no solo \\
\hline $\begin{array}{l}\text { Estradas não pavimentadas } \\
\text { Pastagens } \\
\text { Regiões de vegetação nativa } \\
\text { remanescentes } \\
\text { Vegetação plantada }\end{array}$ & Dissipadores de energia & $\begin{array}{l}\text { - Escadas hidráulicas (enrocamento) } \\
\text { - Bacias de contenção (solo e rocha) }\end{array}$ \\
\hline $\begin{array}{l}\text { Estradas não pavimentadas } \\
\text { Pastagens } \\
\text { Margens de Cursos d'água } \\
\text { Regiões de vegetação nativa } \\
\text { remanescentes } \\
\text { Vegetação plantada }\end{array}$ & Estabilizadores do solo & $\begin{array}{l}\text { - Pequenos barramentos (enrocamento, madeira ou } \\
\text { bambu), } \\
\text { - Plantio de vegetação }\end{array}$ \\
\hline
\end{tabular}

Dessa forma, para a localidade em estudo está sendo sugerida uma listagem de espécies para recuperação ambiental das áreas degradadas. Esta listagem foi preparada com base em referências bibliográficas consultadas, assim como também na observação de campo em canteiros ecológicos (CAMARGO, 2016). Estudos que vêm sendo desenvolvidos no bioma Cerrado apontam para o seu grande potencial econômico, especialmente nas áreas de: alimentos - já se conhecem cerca de 80 espécies vegetais que fornecem frutos, sementes ou palmitos que servem para a alimentação humana; produção de fibras; produção de cortiça - existem cerca de 20 espécies que já são utilizadas para esse fim; produção de tanino; produção de gomas, resinas, bálsamo e látex; produção de óleo e gorduras; uso medicinal - mais de 100 espécies vegetais são usadas para a cura e prevenção de doenças; plantas ornamentais; artesanato; e plantas apícolas (DIAS, 1992). De maneira a dialogar com a literatura acerca da região, foram levantadas as espécies de importância econômica de ocorrência no bioma Cerrado, conforme sua presença em grupos de importância econômica, como se pode ver na Tabela 9 para serem utilizadas nestes plantios descritos.

As atividades recomendadas para a proteção e recuperação ambiental, resumidos na Tabela 10, são relativamente fáceis de serem concretizados, de baixo custo e muitos representam alternativas aos equipamentos ou obras de engenharia mais sofisticada. As medidas propostas, apesar de simples, são eficientes para o controle da degradação ambiental pelas atividades agrosilvopastoris. Para os cálculos financeiros fez-se uma estimativa, baseada em Chaves et al., 2012 levando-se em consideração os preços médios básicos praticados na Região Serrana do Estado do Rio de Janeiro no ano de 2011, para a recuperação de um hectare de área degradada.

Tabela 9: Principais espécies nativas do bioma cerrado.

\begin{tabular}{|l|l|}
\hline Espécies frutíferas & Espécies ornamentais \\
\hline $\begin{array}{l}\text { Neste grupo destaca-se a ocorrência das seguintes espécies: Araçá } \\
\text { (Psidium bergiana), araticum (Annona crassiflora), bruto (Annona }\end{array}$ & $\begin{array}{l}\text { Entre as espécies ornamentais encontradas destaca-se a } \\
\text { presença de canafístula (Peltophorum dubium), com } \\
\text { spinensis), cagaita (Eugenia dysenterica), caju (Anacardium humile), } \\
\text { potencial de uso em arborização urbana, caraíba (Tabebuia } \\
\text { jatobá (Hymeneae stigonocarpa), mutamba (Guazuma ulmifolia) e caroba (Jacaranda decurrens) e também indicada } \\
\text { pequi (Caryocar brasiliensis). O pequi e a cagaiteira como espécies } \\
\text { pe maior potencial comercial, inclusive contribuindo com economia } \\
\text { chrysotrica) e o Pau D'arco (Tabebuia ochraceae) e sombra } \\
\text { regional da região do cerrado }\end{array}$ \\
\hline Espécies produtoras de Madeiras Nobres \\
\hline $\begin{array}{l}\text { O bioma Cerrado tem a presença de espécies produtoras de madeiras nobres, cita-se: a aroeira (Myracrodruon urundeuva), } \\
\text { braúna (Schinopsis brasiliensis), caraíba (Tabebuia caraiba), gonçalo (Astronium fraxinifolium), guatambu (Aspidosperma }\end{array}$ \\
$\begin{array}{l}\text { pyrifolium), jacarandá (Dalbergia violacea), jatobá (Hymenaea stigonocarpa), pau d'arco (Tabebuia ochracea), pau d'óleo } \\
\text { (Copaifera langsdorfii), pau sangue (Pterocarpus violaceus), sucupira (Bowdichia virgilioides) e vinhático (Plathymenia reticulata). }\end{array}$ \\
Todas estas espécies, produtoras de madeiras nobres, têm ocorrência regional e são utilizadas pelas serrarias.
\end{tabular}


Quadro 10: Planilha de Custos (um hectare) - Ano 2012.

\begin{tabular}{|l|l|}
\hline ELEMENTOS DE DESPESAS PRINCIPAIS & VALORES (R\$) \\
\hline CONSULTORIA TÉCNICA AGRÍCOLA-AMBIENTAL & $70,00 /$ hora \\
\hline MÁQUINAS* & $100,00 /$ hora \\
\hline MÃO DE OBRA** & $40,00 /$ dia \\
\hline ADUBOS + BASES (redução do pH) & $1.000,00$ \\
\hline MUDAS E SEMENTES + Frete*** & $2.800,00$ \\
\hline
\end{tabular}

*O uso de máquinas pode não ser necessário em certas intervenções. Entretanto, havendo a necessidade de seu uso, o número de horas de trabalho irá depender da experiência do tratorista, das intervenções necessárias e da dificuldade encontrada no local.

** O custo do projeto pode ser reduzido também caso se aproveite mão-de-obra disponível na família ou se o local possibilitar acesso fácil para transporte dos materiais.

$* * * O$ custo do projeto pode ser reduzido significativamente caso se opte pela produção de mudas no local.

\section{CONCLUSÕES}

Pode-se concluir que a metodologia de Martins Júnior (2014), utilizada para avaliação dos impactos ambientais provocados nos solos na região do município de São Francisco, possibilitou a observação e o apontamento das regiões mais críticas sob o ponto de vista do estado da Degradação (eD). Assim, considerando-se toda a contextualização política, socioeconômica e ambiental, além da aplicação desta metodologia de Martins Júnior (2014) na fase inicial de reconhecimento da qualificação dos impactos, no caso específico do município de São Francisco, pôde-se constatar que os recursos naturais estão sendo cada vez mais degradados em razão das prioridades dadas às atividades econômicas em detrimento da conservação e de políticas corretas para o planejamento de uso do meio ambiente.

Portanto, pela aplicação dos procedimentos descritos em Martins Júnior (2014) pode ser provado e constatado, por meio das avaliações a campo, que as regiões (ou bacias hidrográficas) do local de estudo estão em situações críticas no que diz respeito ao estado da Degradação (eD) do meio físico. Assim, fica também evidenciado que esta metodologia pode somar-se a outros conjuntos de métodos eficientes atualmente existentes para a avaliação de impacto ambiental.

AGRADECIMENTOS: Os autores agradecem ao Departamento de Geologia da Universidade Federal de Ouro Preto, pela aprovação do projeto de pesquisa no âmbito do Programa de Pós-graduação em Evolução Crustal e Recursos Naturais (Doutorado). À Fundação Rural Mineira (RURALMINAS), por ceder, gentilmente, as informações fundamentais para as análises progressivas e regressivas da degradação do cerrado, ao geógrafo Vitor Alves Souza, pelo apoio nas atividades cartográficas que envolveram a utilização do software ArcGIS e QGIS e a historiadora Elodia Honse Lebourg pela estruturação e revisão da língua portuguesa no texto do artigo. E também a Coordenação de Pessoal de Nível Superior (CAPES).

\section{REFERÊNCIAS}

BRANDÃO, Z. N.; BEZERRA, M. V. C.; SILVA, B. B.. Uso do NDVI para determinação da biomassa na Chapada do Araripe. In: SIMPÓSIO BRASILEIRO DE SENSORIAMENTO REMOTO, 13. Anais. São José dos Campos: INPE, 2007. p. 7581.

CAMARGO, P. L. T.. Valoração ambiental da Cachoeira da Serrinha (Parque Estadual do Itacolomi) Mariana/MG.
Dissertação (Mestrado em Sustentabilidade) - Universidade Federal de Ouro Preto, Ouro Preto, 2014.

CHAVES, T. A.; ANDRADE, A. G.; LIMA, J. A. S.; PORTOCARRERO, H.. Recuperação de áreas degradadas por erosão no meio rural (Manual Técnico). Niterói: Programa Rio Rural, 2012. 
CODEMIG. Companhia de Desenvolvimento Econômico do Estado de Minas Gerais. Laudo de Avaliação dos Imóveis Rurais da Bacia Hidráulica da Barragem Jequitaí I, em Minas Gerais. Belo Horizonte: CODEMIG, 2013.

DIAS, B. F. S.. Alternativas de desenvolvimento dos cerrados: manejo e conservação dos recursos naturais renováveis. Brasília: FUNATURA, 1992.

MARTINS JÚNIOR, P. P.; ENDO, I.; CARNEIRO, J. A.; NOVAES, L. A. A.; PEREIRA, M. A. S.; VASCONCELOS, V. V.. Modelo de Integração de Conhecimentos Geológicos para Auxílio à Decisão Sobre Uso da Terra em Zonas de Recarga de Aquíferos. Revista Brasileira de Geociências. v.36, n.4, p.651-662, 2006.

MARTINS JÚNIOR, P. P.; CARNEIRO, J. A.; NOVAES, L. A. A., VASCONCELOS, V. V.; ANDRADE L. M. G.; PAIVA, D. A.. Modelagem Geo-ambiental e Interdisciplinar para Ordenamento do Território com Corredores Florestais Ecológico-econômicos. Revista de Geologia, v.21, n.1, p.7997, 2008a.

MARTINS JÚNIOR, P. P.; CARNEIRO, J. A.; ENDO, I.; ANDRADE, L. M. G.; NOVAES, L. A. A.; PAIVA, D. A.. Agricultura, Conflitos entre a Gestão Territorial e Uso de Áreas de Zonas de Recarga de Aquíferos. In: ENCONTRO NACIONAL DA ANPPAS, 4. Anais. Brasília, 2008b.

MARTINS JÚNIOR, P. P.; CARNEIRO, J. A.; ENDO, I.; MARQUES, A. F. S. M.; VASCONCELOS, V. V.; NOVAES, L. A. D'A.; ANDRADE, L. M. G.; JANO, D. R.. Lógica para Modelos de Integração de Conhecimentos para Auxílio à Decisão Plantios Florestais Ecológico-econômicos em Zonas de
Recarga de Aquíferos. Revista Brasileira de Geociências, v. 40, n.1, p.80-98, 2010.

MARTINS JÚNIOR, P. P.; FERREIRA, O. C.; VASCONCELOS, V. V.; JANO, D. R.. Zoneamento Ecológico-Econômico e Desenho de Uso Optimal dos Territórios de Bacias Hidrográficas. Revista Economia \& Energia, Rio de Janeiro v.14, n.76, 2010.

MARTINS JÚNIOR, P. P.; COUTINHO, C. S.; VASCONCELOS, V. V.; CARNEIRO, J. A.; HADAD, R. M.; JANO, D. R.; MELO, J. W.; ALVARENGA, L. J.; FERNANDES, M. M.; BRITTO, L. O. O.; CLAUS, R. P.; MACHADO, J. L.; HORTA, M. M. X.; CORREA, T. O.; ENDO, I.. Sistemas de Arquitetura de Conhecimentos e de Auxílio à Decisão na Gestão Geo-Ambiental e Econômica de Bacias Hidrográficas e Propriedades Rurais. Ouro Preto, 2012.

MARTINS JÚNIOR, P. P.. Gestão de bacia hidrográfica Instrumentos: o quê e para quê. Ouro Preto e Belo Horizonte: Apostila Pré-Livro, 2014.

OLIVEIRA JÚNIOR, A. F.. Valoração econômica da função ambiental de suporte relacionada às atividades de turismo. Tese (Doutorado) - Universidade Federal de São Carlos, São Carlos, 2004.

ROUSE, J. W.; HAAS, R. H.; SCHELL, J. A.; DEERING, D. W. Monitoring vegetation systems in the great plains with ERTS. In: EARTH RESOURCES TECNOLOGY SATELLITE-1 SYMPOSIUM, 3, PROCEEDINGS. Anais. Washington, 1973.

TAFURI, A. C.. Valoração ambiental do Parque Estadual do Itacolomi, Ouro Preto, Minas Gerais. Belo Horizonte, UFMG, 2008. Tese de mestrado.

A CBPC - Companhia Brasileira de Produção Científica (CNPJ: 11.221.422/0001-03) detém os direitos materiais desta publicação. Os direitos referem-se à publicação do trabalho em qualquer parte do mundo, incluindo os direitos às renovações, expansões e disseminações da contribuição, bem como outros direitos subsidiários. Todos os trabalhos publicados eletronicamente poderão posteriormente ser publicados em coletâneas impressas sob coordenação da Sustenere Publishing, da Companhia Brasileira de Produção Científica e seus parceiros autorizados. Os (as) autores (as) preservam os direitos autorais, mas não têm permissão para a publicação da contribuição em outro meio, impresso ou digital, em português ou em tradução. 